\title{
The Teaching of Reading Comprehension under the Psychology Schemata Theory
}

\author{
Chao Zhang \\ School of Foreign Languages, Qingdao University of Science and Technology, Qingdao, China \\ Email: zhang_chao75@163.com
}

\begin{abstract}
With the globalization and the increase in foreign exchanges, Chinese students have to read more materials in English than ever. To help improve Chinese students' reading comprehension skill, the author discusses in the paper the psychology schemata theory and its implication in the teaching of reading comprehension and advances some constructive suggestions.
\end{abstract}

Index Terms - the teaching of reading comprehension, the psychology schemata theory, the implication

\section{INTRODUCTION}

For students of both English and non-English majors in China, reading ability has been considered one of the most important skills that they should acquire. Traditionally, in the teaching of language comprehension, the emphasis has been almost exclusively on the language to be comprehended but not on the reader or other factors. In this view, students' failures to comprehension are always due to some language-specific deficits, for example, their inadequate knowledge of vocabulary and grammar. But it has also been found that some students who do not have language problems are still unable to comprehend what they read in English. Just as Widdowson (1984) says, the acquisition of linguistic skills does not mean to guarantee the consequent acquisition of communicative abilities in a language.

Since 1960s, ESL reading theory has come under the influence of psycholinguistics and Goodman's (1971) psycholinguistic model of reading, that is, the Schema Theory. And the ESL reading comprehension study is to be talked about from this perspective.

\section{SCHEMATA THEORY AND ITS PSYCHOLINGUISTIC MODEL}

A schema is a structure in semantic memory that specifies the general or expected arrangement of a body of information. The notion of a schema is not new in psychology. It is generally associated with the early work on story recall by Bartlett (1932). He argued that, "it is fitting to speak of every human cognitive reaction - perceiving, imaging, remembering, thinking and reasoning - as an effort after meaning. He argued that memory is active, constructive, and schematically determined. Adults better summarize and remember stories that come from their own culture than they do stories from other cultures when those other cultures have distinctly different expectations about storytelling forms. Such expectations are called schemata. Schemata are, in other words, mental structure acquired through many experiences with an event or in routine by setting up their expectations for what usually will happen and helping them interpret what does happen and remember what in fact did happen on particular occasions both typical and unusual. Schemata are, in turn, continually modified by experiences. In a broad sense, there are two types of schemata - content schemata and formal schemata. Content schemata contain general or specific information on a given topic. Formal/textural schemata contain information about how rhetoric is, or ought to be, organized (Carrell 1998).

Schemata Theory is based on Goodman (1967)'s psycholinguistic model that reading is a guessing game. The basic idea of the theory is that human memory consists of high levels of structures known as schemata, each of which encapsulates our knowledge about everything connected with a particular object or event. Coady (1979) has elaborated on this basic psycholinguistic model and has suggested a model in which the ESL reader's background knowledge interacts with conceptual abilities and process strategies, more or less successfully, to produce comprehension.

As Kant claimed as long ago as 1781, that background knowledge plays a role in (reading) comprehension, so that new information, new concepts, and new ideas only have meaning when they can be related to something the individual already knows. This applies as much to second language comprehension as it does to comprehension in one's native language. Recent empirical research in the field of schema theory has demonstrated the truth of Kant's original observation.

According to schema theory, the process of comprehension is guided by the principle that every input is mapped against some existing schema and that all aspects of the schema must be compatible with the input information. This principle results in two basic models of information processing, called bottom-up and top-down processing. Bottom-up processing is evoked by the incoming data; the features of data enter the system through the best fitting, bottom-level schemata. Schemata are hierarchically organized, from most general at the top to most specific at the bottom. As these bottom-level schemata converge into higher level, more general schemata, these too become activated. Bottom-up processing is, therefore, called data-driven. Top-down processing, on the other hand, occurs as the system makes 
general predictions based on higher level, general schemata and then searches the input for information to fit into these partially satisfied, higher order schemata. Top-down processing is therefore, called conceptually driven. An important aspect of top-down and bottom-up processing is that both should be occurring at all levels simultaneously (Rumelhart 1980). Bottom-up processing ensures that the readers will be sensitive to information that is novel or that does not fit their ongoing hypothesis about the content or structure of the text; top-down processing helps the readers to resolve ambiguities or to select between alternative possible interpretations of the incoming data.

Thus, a reader's failure to activate an appropriate schema during reading results mostly in a mismatch between what the writer anticipates the reader can do to extract meaning from the text and what the reader is actually able to do. There are at least three possible reasons to account for it. For one thing, readers may not have the appropriate schemata the writer anticipated. So they simply cannot understand the concept being communicated. For another, readers may find a consistent interpretation of the texts, but may not find the one intended by the writer. In this case, readers will understand the text, but will misunderstand the writer. Finally, readers may have the appropriate schemata, but the writer does not provide sufficient clues in the text for them to effectively utilize a bottom-up skill to activate the content schemata the reader may already process.

\section{IMPLICATION IN THE TEACHING OF READING COMPREHENSION}

Based on the above analysis, the schemata can improve reading comprehension, and reading, in turn, can help readers build new and correct schemata (Zhang Li, 2006). What a good teacher should do is to help students facilitate reading comprehension by making use of the schemata. We can achieve this goal through the efforts made in three aspects.

\section{A. Enrich Students'Schemata Structure and Enlarge Students' Background Knowledge}

Language is the carrier of cultures, so it is important to strengthen the teaching of cultural background knowledge in the teaching of reading comprehension. For different peoples, their traditions, views and norms, etc. toward the same thing may vary a great deal or even conflict because of cultural differences. Students, therefore, have to equip themselves with related background knowledge on different cultures to achieve good comprehension of the reading materials. Otherwise, they are less likely to make correct judgments and predictions of the questions while they are reading the articles. In view of this, it is necessary for a teacher to strengthen his teaching of the related cultural background knowledge of the target language, besides the teaching of language itself. Students can consequently form new schemata about different cultures and improve their reading comprehension. What's more, students' interest in reading will be greatly boosted.

\section{B. Cultivate Students'Ability to Make Prediction and Association of the Reading Material}

Psychological schemata theory comes from practice; it also has practical guide. Saussure, founder of modern linguistics reckons that Speech activity is heterogeneous and language is homogeneous. Making prediction means to build a psychological schema based on the information of the reading material. According to F. Smith, making prediction is the core of reading comprehension and also the basis for us to understand the world around us. The establishment of prediction-making schemata is dependent on what has been stored in our brain such as semantics, syntax and word meanings and the clues hidden in the reading material. In the teaching of reading comprehension, teachers should guide students to broaden their thinking and inspire them to make prediction from seemingly irrelevant information and extract related information from the brain so that students can gradually enhance their self-awareness of making prediction and association.

\section{Enrich Students'Schemata of Different Writing Styles}

In the reading process, readers will identify the writing style of the material and form the schemata in their minds. They will use all kinds of knowledge, such as knowledge of the discourse and of the socio-linguistic rules to select the relevant schemata to get the theme and structure of the article. With the knowledge of the theme and structure, students can achieve a better understanding of the reading material. Teachers should help students analyze the style, structure and theme of the material before students begin to read it so that students can develop stylistic schemata in their minds. Once students have mastered the stylistic schema, they will process information more effectively and hence improve their reading comprehension.

\section{Activate Students' Existent Content Schema and Help to Create their New Content Schema}

According to schema theory, the new input information, decoding and encoding are all dependent on the existent schema. The input information must be matched with these schemas to complete the process of information processing. For many students, reading is a passive process and they just passively absorb the information. In order to improve reading efficiency and quality, teachers should develop students' cultural sensitivity and activate students' existing schemata through the organization of class discussions on the subject of reading material. Teachers are advised to make a careful selection of the reading material so that students can achieve the effective accumulation of knowledge and therefore enrich their own content schema. 
As mentioned above, students' failures to reading comprehension are mainly due to the lack of appropriate schemata matching the writers' schemata. Therefore, what teachers should do is to help students activate and make full use of new schemata, when interpreting a text. The teaching of reading comprehension under the psychology schema theory requires teachers to help students construct the new schemata based on students' existent schemata by assisting students to find out the main idea of the text, the links between the chapters and the law the chapters follow. Teachers need to activate students' active thinking, guide them to identify the main points of the passage and the interface between the points to form a matching schema. Teachers should provide background information, such as linguistic forms or content previews, to construct or activate the appropriate schemata. Teachers should ask students to use their brains, to give full play to their creativity and to reflect on material they will read so as to form a correct understanding and inference of the material, build their own new schemata and thus broaden the range of their knowledge. It is very unlikely for students to form at once a suitable schema that matches an article. It takes much time and practice to achieve the goal. Teachers should guide students and offer them opportunities of much practice to help students construct their schemata. Just as a proverb says, "Give a man a fish and he eats for a day. Teach them how to fish and he eats for a lifetime."

\section{REFERENCES}

[1] Bartlett, F. C. (1932). Remembering: A Study in Experimental and Social Psychology. Cambridge: Cambridge University Press.

[2] Carrel, P. L. \& Joan C, Eisterhold. (1998). Schema Theory and ESL reading pedagogy. Interactive Approaches to Second Language Reading. P.L.Carrel et al(ed). Cambridge: Cambridge University Press.

[3] Coady, J. (1979). A psycholinguistic model of the ESL reader. In R. mackay, B. Barkman \& R.B. Jordan (eds.). Reading in a Second Language. Rowley, MA: Newbury House Publishers.

[4] Goodman, K. S. (1967). Reading: A psycholinguistic guessing game. Journal of the Reading Specialist 6/1

[5] Goodman, K. S. (1973). On the psycholinguistic model of teaching reading. In F. Smith(ed.). Psycholinguistics and Reading. New York: Holt, Rinehart and Winston.

[6] Rumelhart, D. E. (1980). Schemata: The building blocks of cognition. Theoretical Issues in Reading Comprehension. R. J. Spiro et al(ed). Hillsdale N.J.: Eelbaum.

[7] Widdlowson, H. G. (1984). Teaching language as communication. Oxford: Oxford University Press.

[8] Zhang Li (2006). The Psycholinguistic Schema Theory and ESL Reading Methodology. In Teaching English China Vol.29.No.3. Beijing: Foreign Language Teaching and Research Press.

Chao Zhang was born in Linyi, China in 1975. She received her M.A. degree in linguistics from Qingdao University of Science and Technology, China in 2008.

She is currently a lecturer in Foreign Languages School, Qingdao University of Science and Technology, Qingdao, China. Her research interests include teaching methodology and translation theories and practice.

Ms. Zhang is a member of Translation Institution of Qingdao University of Science and Technology. 